\title{
Optimization of the Financial Strategy of Bilibili Barrage Website from the Perspective of Social Responsibility
}

\section{Yifei Zhao $^{1^{*}}$ Yicheng Zhao $^{2}$}

1. Jilin University of Finance and Economics, Changchun, Jilin, 130022, China

2. Suzhou Branch of Construction Bank, Suzhou, Jiangsu, 215021, China

\begin{tabular}{|c|c|}
\hline ARTICLE INFO & ABSTRACT \\
\hline Article history & \multirow{7}{*}{$\begin{array}{l}\text { This paper studies the modern corporate financial strategy from the per- } \\
\text { spective of corporate social responsibility performance, using the Internet } \\
\text { video site Bilibili as an example to analyze, starting with Bilibili's strate- } \\
\text { gic environment, based on financing, investment, distribution, and social } \\
\text { responsibility. This paper comprehensively analyzes its advantages and } \\
\text { disadvantages from its financial strategy. Finally, from the perspective } \\
\text { of social responsibility, from three aspects of investment, financing, and } \\
\text { profit distribution, the authors made optimization suggestions for Bilibi- } \\
\text { li's financial strategy. }\end{array}$} \\
\hline Received: 15 July 2020 & \\
\hline Revised: 22 July 2020 & \\
\hline Accepted: 9 October 2020 & \\
\hline Published Online: 16 October 2020 & \\
\hline Keywords: & \\
\hline Financial strategy & \\
\hline
\end{tabular}

\section{Introduction}

$\mathrm{T}$ his paper takes bilibili, a video website in the Internet industry (English name: Bilibili, hereinafter referred to as B Station), starting from the introduction of the existing financial strategy analysis of Station B, this paper combines the perspective of corporate social responsibility and analyzes the performance of social responsibility of Station B from the perspective of stakeholders.

\section{Financial Strategy Analysis of Station B}

Different from other video websites at present, B station has a unique "UP main +OGV" mode, forming a good ecosystem of original content. From the investment trend of B station in recent years, it is not difficult to see that On the basis of retaining the core users of the original quadratic element, B station strives to attract non-quadratic culture enthusiasts with multiple partitions such as live broadcast and film and television ${ }^{[1]}$.

*Corresponding Author:

Yifei Zhao,

Female, native of Huaian, Jiangsu province, undergraduate;

Correspondence address: School of International Exchange, Jilin University of Finance and Economics, Changchun, Jilin, 130022, China;

Research direction: E-commerce, accounting and Finance;

E-mail: 739466492@qq.com.

Yicheng Zhao,

Female, native of Huai'an, Jiangsu Province, bachelor;

Research direction: bank management, corporate financial management;

E-mail: zyc_orgcat@qq.com. 


\subsection{Financing Channels and Financing Scale}

The financing method of B station at the present stage is equity financing. After three years of venture capital from 2015 to 2017, the company went public with its IPO on March 28, 2018, and then went through four rounds of strategic financing. According to data, Tencent investment has paid close attention to B station in 2015, and in 2019 Tencent announced that it will cooperate with B station in the future.

In 2018, B Station took advantage of the "Dongfeng" of its listing to expand its financing scale.In October 2018, Tencent announced an investment of 317 million US dollars in B Station to increase its stake to around 12\%. On February 13, 2020, Tencent again invested in B Station to increase its stake to $18 \%$; In February 2019, Alibaba announced about 24 million shares, holding about 8\% of the shares; On April 9, 2020, SONY announced a strategic investment of $\$ 400$ million in $B$ station, and the two sides will carry out in-depth cooperation in various fields.

\subsection{Investment Direction and Scale}

In recent years, Station B has invested in production of Chinese opera, game agency, live broadcast of e-sports and documentary. The large investment behaviors of B Station in recent years are mainly after 2016. As Chen Rui, CEO of B Station, said: Station B needs to "get out of the loop". If Station B wants to establish a firm foothold in the future video website industry, it should not be limited to the positioning of a small circle with the same two dimensions. We need to transform into a benign ecological community that is based on two-dimension culture and supplemented by popular Internet "we media". Under the large investment scale, the operating cash flow of B station is not optimistic. During the expansion period, it is normal for enterprises to frantically absorb funds for development. However, Station B is obviously hungry for funds, and its operating cash flow is only enough to "feed the family", with low risk prevention and control capability for emergencies. Encouragingly, since 2017, the cash flow from operating activities of Station B has been positive, which reflects the certain effect of investment from the side.

\subsection{Investment Effect and Dividend Distribution Strategy Analysis}

The return on total assets of Station B from 2015 to 2018 is not very optimistic. In 2016, the exclusive agent of B station mobile game "Fate/Grand Order" national service, the overall rate of return has improved, after which
B station launched a series of subsequent investments. From 2019 to 2020 Station B also focuses on investing in opera production. Although it has not been reported in the financial report, it can be expected that the operation managers of station $B$ continue to explore new profit models while maintaining good user experience ${ }^{[2]}$.After B station went public in 2018, it attracted a lot of investment. At present, there is no public dividend distribution plan for B station. It can be seen from the phenomenon that many big capital have settled in B station in the hope of joining the "ship full of young people", That B station is a very promising new video website in the eyes of many domestic Internet capital. But the gap in B's dividend distribution will affect the confidence of injected capital in the future.

\section{Analysis of Social Responsibility Perfor- mance in the Current Financial Strategy of Station B}

This part will analyze whether the corporate social responsibility fulfilled by $B$ station is in place from the perspective of its stakeholders and in combination with its financial strategy. Stakeholders are divided into internal and external stakeholders. The analysis objects of internal stakeholders are mainly shareholders and employees, while the analysis objects of external stakeholders are mainly consumers and social environment.

\subsection{To Internal Stakeholders}

From the perspective of shareholders, the data show that the return on equity of B station over the past 12 months is $-18.41 \%$. The biggest problem of Station B at the present stage is the serious net loss, which is like a "bottomless hole", and it is impossible to make a stable dividend plan. At the same time, due to the lack of profit points, B's profitability is also worrying. Although it is a promising new video site with investments from Tencent, Alibaba and SONY, it still needs to strengthen its performance of shareholder responsibilities. From the perspective of employees, low profitability leads to low wages for employees, which is the dilemma facing Station B at this stage. For B station at the present stage, the problem of not making profits makes it the basic responsibility in social responsibility. The problem of not making profits makes its basic responsibility in social responsibility -economic responsibility is barely fulfilled. The problem that the salary of employees is not competitive in the same industry will lead to the lack of talents in the later stage. 


\subsection{To External Stakeholders}

From the perspective of consumers, besides the 2-dimensional culture with danmu culture as the core competitiveness, the absence of patch advertising is also an important aggregation point of users. The choice of B station to give up the $\mathrm{AD}$ revenue to maintain the user experience itself is a respect for consumers, but also give up the traditional $\mathrm{AD}$ as the main profit point. In fact, in the previous analysis, we can also see that the lack of profit point is the main contradiction at the current stage of B station. Although Station B maintains the in-station setting without $\mathrm{AD}$ placement, if it cannot find a new profit model as soon as possible, it will be difficult to maintain the in-station construction and bring consumers a good video website viewing experience in the case of continuous $\operatorname{loss}^{[3]}$.Even so, Station B still adheres to the attitude of being responsible to consumers to build community culture in the station. In the process of multi-investment in B station, some users who do not belong to the two-dimensional culture circle also enter into the community. How to balance the interest circle between new users and old users is also what B station has been trying to explore. From the perspective of social environment, the core users of B station are urban young people under the age of 28 . How to correctly guide the values of youth, spread positive energy, and strengthen content review? Users in B station can apply to become "discipline committee member" to maintain danmu etiquette spontaneously from the user end. In the face of difficulties, No matter making donations to the epidemic area or offering free membership to the people of the epidemic area, Station B did not evade its ethical and philanthropic responsibilities because of its problems in profitability and return on investment.

\subsection{Financial Strategy Analysis of Station B}

As an emerging video website, B station has achieved good results in its early stage of development. However, from the analysis of financing, investment and distribution in its financial strategy, it does have some problems in cost, revenue and investment ideas.

\subsubsection{High Costs Affect Sustainable Development}

From 2018 to 2020, the users of B station are surging, which brings strong server pressure, huge hardware maintenance costs and software development costs, which has become a reason for B station's poor performance in recent financial statements. Secondly, B station is mainly about 2-dimensional culture, and the annual copyright expense is also a large sum of money. In 2014,
B station put forward the "Xin-Fan Contract Plan", in which users can voluntarily pay rewards to their favorite TV series, but the huge copyright fee is only a drop in the ocean ${ }^{[4]}$. Finally, the cost of acquiring effective users in the video website industry is soaring, and in the face of the gradual inefficiency of traditional marketing means of acquiring users, whether B station can find a new marketing method is also the focus of cost saving.

\subsubsection{A Single Revenue Structure, Mired in a "Bottomless Pit of Money"}

Singleness of profit point is caused by singleness of user object. There are many fans of 2-dimensional culture in B station. If they cannot find new ideas in the face of profit dilemma, they are likely to lose their unique "foundation". The multi-directional investment but low return of B station also proves that the special user group makes it difficult to expand other businesses.

\subsubsection{By the Shackles of Two - Dimensional Cul- ture, "Out of the Circle" Difficult}

In recent years, Station B has been involved in the direction of live broadcasting, documentaries, and variety shows and so on. It hopes to attract more users with different demands through the partition of the complete station, but the effect is not so good. In addition, the influx of a large number of non-quadratic users also has a certain impact on the cultural ecology of the quadratic community, making it more difficult to "get out of the circle".

\subsubsection{Lack of "Core Business" Investment}

Game and cartoon are the key content of B station's early investment, but in the face of limited funds, B station's investment in animation is obviously insufficient. At present, B station is also actively making strategic investment in Guomin. Whether it can seize the investment opportunity in the rise of Guomin and create its own guomin works with absolute right of discourse is the key to whether It can establish its "core business" in the future ${ }^{[4]}$.

\section{Optimization of Financial Strategy in B Station from the Perspective of CSR Fulfill- ment}

In the further development, B should use positive and stable financial strategies to fully combine its own advantages with financial strategies. Actively seize external opportunities to improve the competitiveness of 
enterprises and take the path of sustainable development. Aiming at the problems existing in the financial strategy of B station, this paper proposes optimization countermeasures from three aspects of investment, financing and profit distribution respectively from the perspective of social responsibility.

\subsection{Optimization of Investment Strategy Based on Social Responsibility}

\subsubsection{Optimize the Business Structure and Tap the Potential of Users' Consumption}

Combined with the diversified investment strategy of B station, B station needs to optimize its business structure in the future, deeply explore the pan-quadratic industrial chain, and tap the potential of user consumption. In view of the downturn in the comic industry, B station can gradually launch the "bilibilicomic" APP through the merger with netease comics to discover users from video websites and increase user stickiness. While cultivating the ecology of original comics, explore the potential market for mature IP cooperation. In view of the high proportion of game income, B station can hold offline activities with related themes, produce peripheral products, and link with live broadcast area.

\subsubsection{Broaden Investment Ideas and Shoulder the Responsibility of Spreading Positive Energy}

At the present stage, the investment strategy of Station B is still centered on products, and at the same time, we can also consider broadening the investment ideas. For example, Station B could invest in an official MCN organization ${ }^{[5]}$.To actively explore the quantitative changes of the platform and UP mainstream, invite unsigned small and medium-sized UP owners to join the official MCN organization, cultivate core UP owners in the station, and establish an effective ecological closed loop of we media in the station. UP has always been the core productivity of B's original content. Although B station has launched "incentive plan", it cannot solve the employment problem of "we media" for UP owners in many districts. Further improving the living environment of more UP zones is also the main project that B station should invest in in the future.

\subsubsection{We Should Cater to the Investment Re- quirements of Socially Responsible Investors and Set up Corporate Image}

As a gathering place of 2-dimensional culture, one of the labels of B station is youth, and its investment ideas have always been centered on the pan-2-dimensional industrial chain where young people consume a lot. This also requires B to establish a qualified positive corporate image in the investment and construction of the pan-quadratic industrial chain. The mainstream users of B station have always been young people born in the 1990s. It can be said that the image of B station is the epitome of its user group. Catering to the investment requirements of socially responsible investors and setting up an excellent corporate image in the construction of its own industrial chain are the new requirements of users, customers and the society for this emerging video website. At the same time, in recent years, many animation works that "tell A good Chinese story" have entered the public's vision. As a gathering place of 2-dimensional culture, Station B should also shoulder the responsibility of carrying forward Chinese traditional culture in new forms. Whether it is creation, supervision or promotion, how to present excellent Chinese stories to users is also a question that B station needs to complete as a new video website.

\subsection{Financing Strategy Optimization Based on Social Responsibility}

\subsubsection{Establish a Financing Structure with Bal- anced Risk of Stakeholders}

Although the industry has a positive attitude towards the future development of B station, but consecutive years of losses are not optimistic about the fact. With the investment from Tencent, Ali and SONY, B has no difficulty in financing, but relies entirely on equity financing, which is not conducive to risk control. Establishing a financing structure with balanced risk of stakeholders is an important issue that B should solve in the financial strategy at this stage. Most of the financing in B station now comes from the direct financing in the stock market, and the shareholders belong to outsiders ${ }^{[6]}$.For shareholders, the information grasped by outsiders is ultimately limited. There is no information disclosure in the internal management and future strategic planning of B station, and there is also a gap in supervision. In addition, the unsatisfactory profit indicators in three consecutive years of financial statements, Station B did not perform its social responsibility to shareholders well. Therefore, in the future, B station must establish a financing structure with balanced risks for stakeholders, both for direct investors and indirect investors.

\subsubsection{Innovative Financing Methods}

The main financing method of Station B at the present 
stage is equity financing. In order to cope with the financing problems in the subsequent expansion period of enterprises, Station B can try to make innovations in financing methods ${ }^{[7]}$. First of all, users in Station B are sticky-sticky and pay more attention to the future development of the website. Post-90s users, as the new generation of economic power, have certain demands for investment and financial management. Therefore, Station B can take advantage of this special advantage to establish "user fund" for different financing methods. Secondly, Station B can also try the way of debt financing to deal with the shortage of funds for rapid expansion in the short term, which can be used for hardware construction and R\&D expenses, without affecting the internal decision-making level of the enterprise. Finally, in the face of high hardware costs such as broadband and servers, B station can try the way of financial leasing, which can not only keep pace with The Times on the equipment to cope with the great changes of broadband and servers in the $5 \mathrm{G}$ era, but also strengthen cost control in expense.

\subsection{Profit Distribution Strategy Optimization Based on Social Responsibility}

\subsubsection{Strengthen Cost Control and Improve Prof- itability}

Facing the high cost, B can focus on two aspects in the financial strategy: one is marketing cost, and the other is r\&d cost. After good cost control, the profitability of B station will be improved to some extent.

\subsubsection{Formulate a Relatively Stable Dividend Distribution Plan}

In view of the status quo of B station, on the basis of ensuring that the financing and investment needs are fully met, the proposal of low normal plus additional dividend policy is put forward. The low normal plus extra dividend policy is suitable for the rapid development stage of the enterprise, which can not only enhance the shareholders' confidence in the sustainable development of the enterprise, but also facilitate the flexible capital dispatching of the enterprise. For the current financial situation of Station B, the low normal plus additional dividend policy can be implemented at the initial stage of substantial profit. The formulation of a stable dividend policy also puts forward a new requirement on the profitability of B station, and the formulation of a financial strategy to strengthen cost control is a guarantee for the smooth implementation of this strategy. a decisive influence on the future survival and development of enterprises. Meanwhile, facing the topic of corporate social responsibility, how enterprises combine financial strategy with social responsibility has become a new issue for the survival and development of enterprises in the new economy and society. Taking B station as an example, this paper analyzes the deficiencies of the existing financial strategy of B station as an emerging video website under the background of the Internet, and makes improvement measures for the financial strategy of B station from the perspective of corporate social responsibility. The main research conclusions are as follows:

First, the relationship between corporate financial strategy and social responsibility is interactive. Appropriate corporate financial strategy is the basis for enterprises to fulfill their social responsibilities. The healthy development supported by corporate financial strategy is indispensable for enterprises to fulfill their social responsibilities smoothly. Corporate social responsibility should be a new goal of corporate financial strategy facing different parts of social responsibility, when formulating financial strategy, enterprises should add phased contents and reserve treatment methods. To ensure the survival and development of enterprises at the same time within the scope of their own development stage, to complete the corresponding social responsibility; the ultimate ideal of the two is that CSR fulfillment and corporate financial strategy complement and promote each other.

Second, the financial strategy of Station B has three aspects: The high cost affects the sustainable development, and the net profit keeps losing money, which reduces the capital confidence. Single investment thinking, lack of "core business" investment without strategic thinking, bound by the two dimensional culture, "out of the circle" difficult.

Thirdly, from the perspective of corporate social responsibility, the countermeasures to optimize the financial strategy of B station from the perspectives of investment, financing and profit distribution are as follows: While optimizing the business structure, B station needs to tap the consumption potential of users, broaden the investment ideas, shoulder the responsibility of spreading positive energy, and meet the investment requirements of socially responsible investors to establish an excellent corporate image. Establish a financing structure with balanced risk of stakeholders and innovate financing 
methods; Strengthen cost control, improve profitability, formulate relatively stable dividend distribution plan to enhance capital confidence.

\section{References}

[1] Jiang Bingyu. Research on Bilibili Profit Model based on financial Analysis [D]. Heilongjiang: Northeast Petroleum University, 2019.

[2] Jiang Bingyu. Research on Bilibili Profit Model based on financial Analysis [D]. Heilongjiang: Northeast Petroleum University, 2019.

[3] Journal of Tongji University, 2019-03-01 (03).8. (in Chinese)
[4] Qin Zihan. Brief Analysis on the Operation Strategy of "B Station" from the perspective of users [J]. New Media Research, 2019:48-49.

[5] MCN organization is a product form of multi-channel network. With the strong support of capital, it can guarantee the continuous output of content and finally realize the stable realization of business.

[6] Zhang Chi. Research on The Financial Strategy of Bright Dairy From the perspective of corporate Social responsibility [D]. Jiangsu: Jiangsu University, 2018.

[7] Liu Qin. Research on Financial Strategy Selection of Internet Enterprises -- A Case Study based on LetV [D]. Chongqing: Chongqing University, 2017. 